\title{
Engendering disaster risk management and resilience- building: the significance of the everyday in evaluations of the exceptional
}

\section{Jordana Ramalho}

The Bartlett Development Planning Unit (DPU), University College London, 34 Tavistock Square, London WC1H 9EZ, UK

Keywords: Gender Resilience Social reproduction; Everyday; Disaster Risk Reduction and Management; Philippines.

\begin{abstract}
This article argues for greater consideration of 'the everyday' within evaluations of 'the exceptional' and presents this as a practical means of engendering disaster risk reduction and management (DRRM) and resilience-building. Building on scholarship from feminist geography, gender and development and feminist political ecology, it charts a new way of theorising disaster risk and resilience from a gendered perspective through the analytic of the everyday, and substantiates this with findings from ethnographic research conducted between 2016 and 2017 in disaster-prone informal settlements in the Philippines. As this case reveals, a focus on the everyday helps to uncover the multiple subjective embodiments of risk and insecurity and the structural systems that underpin related inequalities and exclusions. Crucially, the lens of 'the everyday' also exposes the social reproductive labours and power hierarchies embedded in community-based DRRM and resilience-building programmes; insights which are vital to advancing more inclusive, sustainable and socially just approaches to disaster risk governance and climate change adaptation.
\end{abstract}

\section{Keywords}

Gender; resilience; social reproduction; the everyday; disaster risk reduction and management; Philippines.

\section{Introduction}

Despite growing international awareness about the importance of considering gender in disaster risk reduction and management (DRRM) and climate change adaptation policies and programmes, evidence of any real or substantive commitment to adopting a gendered perspective by the agencies and individuals responsible for implementation remains relatively 
Ramalho - Engendering disaster risk management and resilience-building: the significance of the everyday in evaluations of the exceptional

limited [1-3]. Where 'gender' does feature, it is often restricted to statements about the vulnerability of women and girls owing to their presumed socio-economic disadvantage and exclusion from decision-making processes, relative to their male counterparts. Not only do such interventions (and the assumptions that underpin them) ignore the vulnerabilities of men, boys, transgender and non-gender conforming people during and following such events, but in categorising women and girls as homogenous marginalised subjects, female agency and contributions to DRRM are often rendered invisible. Framing gender and DRRM considerations around vulnerability and exclusion also has implications on the types of interventions that are adopted and perceived as 'addressing gender'. Efforts at gender sensitive programming are often limited to the collection of (binary) sex-disaggregated data about affected persons, the creation of female-specific spaces and services in evacuation centres, and gendered livelihood and economic reintegration projects. Though these are important pursuits in their own right, on their own, they fail to address the power relations and complexities inherent to gendered experiences of disaster and environmental change.

Scholars and practitioners working in the field of gender and development have long voiced similar critiques about issues of gendered essentialism, as well as the emphasis on, and instrumentalisation of, individual capacities and self-determinism over efforts to address the structural injustices and relations of power that underpin inequalities [4-6]. Many have also pointed out the masculinist and colonial roots of development work, and the need to redefine the way that we think about and approach development itself if feminist efforts to engender the sector are ever to be achieved [7-10]. Indeed, the field of DRRM is plagued by a similar ontology rooted in Greco-Roman Christian constructions of 'hazards as disorder - as interruptions or violations of order' [11]:12-13, and depictions of 'large parts of the world as dangerous places for us and ours... [which] serves as justification for Western interference and intervention ... for our and their sakes' [12] (italics in original). As Bankoff [12] attests, '[a]ttributing disasters to natural forces, representing them as a departure from a state of normalcy to which society returns to on recovery, denies the wider historical and social dimensions of hazard and focuses attention largely on technocratic solutions.'

To this day, the term disaster carries particular connotations and assumptions that define what is included and excluded from DRRM and resilience-building discussions. As I argue below, a focus on hazards over the subjective ways in which risks and disasters are understood and experienced, leads to the privileging of technical expertise and solutions over local knowledges and experiences. Attention and resources prioritise emergency response and mitigation, rather than investing in development and capacity-building programmes to address 
Ramalho - Engendering disaster risk management and resilience-building: the significance of the everyday in evaluations of the exceptional

the pre-existing inequalities and exclusions that create conditions of vulnerability and limit the ability of some more than others to 'bounce back better'. Traditional epistemologies of disasters and associated masculinist preoccupations with economic rather than social recovery also inhibit efforts to engender DRRM, by neglecting the multiple affective and material embodiments of risk [3,13-15] and the extensive (feminised) labours that contribute to local resilience [16-21].

In an effort to address some of these oversights and challenges, in this article, I put forth a framework for engendering DRRM that is grounded feminist conceptualisations of 'the everyday'. As I reveal below, focusing on the everyday draws out the multiple and intersecting social, political and structural drivers of endangerment and vulnerability [22], reinforcing risk and disasters as a continuum [23-25] born from pre-existing inequalities. Furthermore, uncovering and making sense of the everyday necessitates engagement with grassroots perspectives and experiences [24] that are all too often silenced or excluded in DRRM and climate change adaptation agendas. This latter point is especially critical given that risk and vulnerability are subjective, socially and spatially contingent conditions [26], and relatedly, as my findings indicate, are gendered in both perception and experience (see also [3,19,27-29].

To introduce this interdisciplinary theoretical approach, I begin with a brief overview of contemporary debates in critical disaster studies and gender and development, bringing them into conversation with one another under a rubric of feminist political ecology. Herein, I also build on the work of established and emerging feminist scholars interested in 'the mundane' practices of everyday life and of social reproduction, and the insights they offer us into gendered political economies [18-20,30-36]. I then present findings from ethnographic research conducted in disaster-prone informal settlements in Metro Cebu, the Philippines, to showcase the relationship between 'the everyday' and 'the exceptional' in the context of risk management and resilience-building. Through this analysis, I reveal the micropolitics informing access to infrastructure and public services and how these translate to gendered embodiments of risk and practices of resilience-building.

Decentring traditional conceptualisations of urban (disaster) risk, my findings suggest that it is not the large scale events classified as disasters in the mainstream that dominate the minds of the urban poor living in 'danger zones', but rather the daily challenges of survival under conditions of incessant financial, livelihood and land tenure insecurity, and associated infrastructural exclusions. I thus argue that encounters with risk (and disaster) constitute an everyday rather than exceptional reality in many low-income areas, and that focussing DRRM solely around major catastrophic events obscures gendered labours and realities and therein 
Ramalho - Engendering disaster risk management and resilience-building: the significance of the everyday in evaluations of the exceptional

limits the efficacy of community-based (CB)DRRM initiatives. Relatedly, I contend that the exceptionality conjured by the term disaster serves to depoliticise of discussions of risk by concealing the socio-political and structural drivers of vulnerability, while also deflecting attention away from the power configurations and actors complicit in the production of risk. I conclude with some reflections on the significance of these insights for DRRM and resilience scholarship and practice, and the opportunities they present for building resilient and sustainable futures grounded in an ethos of care, equity and inclusion.

\section{Gender, risk, and resilience: the significance of 'the everyday:}

The United Nations International Strategy for Disaster Reduction (UNISDR) defines a disaster as a 'serious disruption of the functioning of a community or a society involving widespread human, material, economic or environmental losses and impacts, which exceeds the ability of the affected community or society to cope using its own resources' [37]. International quantifications of what constitutes 'serious disruption' and 'widespread loss' tend to refer to situations where either mortality levels exceed 10 deaths, over 100 people are affected, or where the government requires external support and declares a state of emergency [38]. Disasters therefore depend not only on the destructiveness of a given event, but also on the response capacity and/or willingness of external parties to intervene both during and in its aftermath. What happens when the state has the capacity to respond, but chooses not to? And what about those individuals whose lives are routinely disrupted by economic and environmental shocks, but whose experiences are invisible to those within and outside their communities?

Although levels of economic or material damage are purposefully left unspecified in official definitions to account for those with limited material assets, underlying preoccupations with physical valuations of loss and disruption to economic activities fail to capture the broader embodied and psychosocial impacts of such events on different groups. Indeed, as Bradshaw and Fordham [3] critically assert, many women and girls face a double-disaster due to preexisting norms and power relations whereby the material losses following the main event create numerous 'secondary impacts' on their health and wellbeing that emerge over time, including inter alia increased exposure to violence, time poverty and financial and livelihood insecurity. These 'double impacts of disaster' [3] are often compounded under conditions of chronic stress associated with poverty, land tenure insecurity and/or violence; realities that characterise many of the contexts in which DRRM programmes are operating. There is thus a need not only to reconceptualise disasters as a development issue as Bradshaw and Fordham 
Ramalho - Engendering disaster risk management and resilience-building: the significance of the everyday in evaluations of the exceptional

[3] attest, but also to seek out alternative epistemologies that value and offer space to the perspectives and experiences that have been caricatured if not completely disregarded by the masculinist and technocratic thinking that dominates the DRRM sector [39-41]. The lens of everyday risks offers an insightful frame for engaging in this analysis.

Where disasters are 'defined by actual damages and losses', risk encompasses 'the probability' of adverse consequences following exposure to environmental and anthropogenic hazards under conditions of vulnerability, and is 'counterbalanced by the capacity or resilience' of a system, individual or community to adapt [42] citing [2] (see also [26]). Conceptualised as a state of exposure and defencelessness, vulnerability is produce when external threats merge with internal deficiencies in the capacity of a system or individual to cope with resultant shocks or losses [43]. As I discuss in more depth below, these 'deficiencies' often stem from sustained experiences of discrimination and structural inequality within and across diverse socio-political spaces and scales, which materialise as 'everyday risks'. Everyday risks emerge from (and simultaneously reinforce) conditions of (poverty, underdevelopment and human structural insecurity which jeopardises and limits human development' [44], and (re)produces 'highly inequitable cycles of displacement and exposure' which Allen et al. [42] refer to as 'urban risk traps'. Vulnerability analysis offers an important entry point for thinking about the unequal distributions of everyday risks and disasters within and between populations [45,46]. However, labels of vulnerability must be approached with caution since they often misrepresent and oversimplify people's realities, bypassing 'how one gets from very widespread conditions such as "poverty" to very particular vulnerabilities that that link the political economy to the actual hazards that people face' [26] (italics in original).

In the Philippines as elsewhere, the vulnerability of the urban poor to disasters is frequently attributed to the precarity of settlement locations, prompting large-scale state-driven eviction programmes which are being rolled out in the name of DRRM [47-49]. As I discuss below, such approaches reproduce rather than redress the 'cycles of displacement and exposure' described by Allen et al. [42], and do not interrogate the pre-existing socio-economic inequalities and societal divisions that limit people's access to alternative housing locations. Furthermore, without an understanding of the interactions between extensive (everyday) and intensive (exceptional) risks [50] and the power hierarchies embedded within these dynamics, DRRM and resilience-building initiatives are unlikely to achieve their stated aims. For example, health risks such as those incurred as a result of poor air and water quality, food insecurity, and the spread of infectious and parasitic diseases, are exacerbated in densely populated areas lacking adequate drainage, sewage and solid waste disposal facilities, and become all the more 
Ramalho - Engendering disaster risk management and resilience-building: the significance of the everyday in evaluations of the exceptional

pronounced during floods or heatwaves [23]. Exclusion from public services and isolation from political and legal networks of support also aggravate the vulnerability of the urban poor to chronic and acute stresses [50-52].

Among informal settlers, the adverse effects and number of deaths caused by these everyday risks are significant (and underestimated). Notwithstanding, DRRM and climate change narratives, resources, and attention have maintained a preoccupation with 'intensive risks' or major calamitous events [50]. This is despite the fact that the main impacts of climate change are likely to be through an exacerbation of existing hazards and developmental challenges $[22,25,51,53]$. Focusing on large-scale calamities overemphasises the significance 'the event' in itself, making slow-onset disasters and everyday risk more invisible, despite their damaging and disruptive consequences in the longer term [ibid.] (see also [54]). Appraisals of the poverty-vulnerability nexus as it relates to disasters is thus better conceptualised as a 'continuum of risk from everyday to catastrophic disasters' [23,24] Approaching risk as a continuum directs our attention to the effects of, and interactions between, intensive and extensive risks on communities who must navigate these hazards [54] (see also [50,55]). Similarly, as Allen et al., [42] contend, considerations of everyday risk:

'acknowledge the daily struggles and experiences of those men, women, boys and girls exposed to urbanisation and urban change under risk conditions... [W] hen we seek to establish the causes of everyday risks, the limits between human and natural influences become less evident, especially when analysing these along temporal and spatial scales, as well as considering people's daily practices... Additionally, the lack of knowledge and recording of these risks contributes to their invisibility, which in its turn deepens their internalisation within the most vulnerable households and limits the design and implementation of preventive public interventions.'

According to a multidimensional poverty measure adopted in the Philippines which assesses deprivation through 13 indicators across four dimensions of health and nutrition, education, employment, and access to water, sanitation and secure housing, the proportion of the population considered 'multidimensionally deprived' was estimated at 23.9 percent in 2016 and 17.3 percent in 2017 [56]. 70 percent of the population is also estimated to be working in the informal economy [57], and low wages typical of both formal and informal employment mean that people commonly engage in several income-generating activities simultaneously to make ends meet. As elsewhere in the world, during times of crisis, the burdens of creatively managing household assets tend to be carried by women, who in addition to reducing their personal food intake (by skipping meals for example) also take on multiple jobs known as 'sidelines' to generate additional incomes [58] (see also [35,36,59]). LindioMcGovern [60] similarly notes 'that poor Filipino women, who generally are the ones to attend 
Ramalho - Engendering disaster risk management and resilience-building: the significance of the everyday in evaluations of the exceptional

to the daily needs of the family, are the first to suffer the social psychological impact of the price escalation of food and of other basic daily needs'. The everyday political economy of maintaining social reproduction and related 'feminisation of responsibility and obligation' [4] extends to disaster and post-disaster contexts, in which the reproductive responsibilities associated with care and survival are intensified alongside pre-existing inequalities [20,61-63], furthering the depletion and deterioration of women's bodies, health, and wellbeing more generally [36]. These dynamics are exacerbated in informal settlements, where residents tend to have smaller asset pools on which to draw owing to the above-discussed mutually reinforcing privations of income, housing, services and infrastructure. Such realities have prompted Unterhalter [64] to conceive of slums as 'spatial poverty traps', especially for women and girls for whom these infrastructural deficiencies impose particular challenges on their health, income-generating potential and reproductive responsibilities $[65][66,67]$.

Recognising the centrality of gender, class, ethnicity and other intersecting markers of social difference to the ways that people experience risks and disasters $[27,38,68]$, efforts to engender DRRM and resilience-building can take many insights from feminist political ecology. This body of scholarship draws attention to the gendered dimensions of political confrontations over access to and control over resources and knowledge, as well as gendered interests and engagement in environmental management and activism [69]. For example, Truelove's [13] appraisal of gendered spatialities of water access in Delhi, and the embodied practices deployed by the urban poor in an effort to navigate these exclusions, showcases how access to resources and infrastructural networks are intrinsically connected to social power, with notable implications for women and girls:

'Bodily experiences, including the wear and tear of water labor, water-related health problems, the physical experience of criminalization for illegal practices and the disciplining required for water-related health issues (including diarrhea and menstruation for example), are intimately tied to the experience of urban space and rights. Such embodied experiences serve to re-enforce gendered and classed social differences, materially shaping and constraining physical hardships and life opportunities while discursively producing social differences and particular groups of women as excluded from rights and spaces in the city.'

Doshi's [70-72] Mumbai-based research highlights the centrality of women's social reproductive labours to grassroots movements to contest the displacement of urban poor communities. She reveals how engagement in collective action is itself informed by hierarchies and privileges associated with caste and socioeconomics, decentring the homogenisation of women that often features in appraisals of gendered participation [72]. More broadly, Doshi's work interrogates the 'connections between embodied precarity... social reproduction... and 
Ramalho - Engendering disaster risk management and resilience-building: the significance of the everyday in evaluations of the exceptional

socio-spatial inequalities', and calls for greater consideration of 'how affective intensities work through and shape infrastructures and socio-natural flows' [73]. Both Doshi's and Truelove's findings show that risk and insecurity can be embodied as both vulnerability and agency, and reinforce the importance of contextualising appraisals of risk within the existing socio-political structures that shape people's identities and interactions with one another and their environment. They also expose the ways in which risk and efforts to govern risk intersect with pre-existing exclusions and authorities to create new categories of difference, and emphasise the centrality of gendered practices of care to the sustenance of everyday life. Such knowledge is integral to designing effective DRRM and climate change adaptation interventions, and to ensuring that the objectives and outcomes of policies and programmes are in line with those of intended beneficiaries (rather than presumed to be so) [74].

Indeed, labours of social reproduction, both material and affective, are intrinsically linked to the operationalisation of resilience in people's everyday lives $[18,19]$. Given that there is no 'consensus on what resilience means in practice for different stakeholders, how it is best achieved, and who is, and/or should be responsible for it' [19], particular attention must be paid to the nature and terms of gendered participation in CBDRRM, to ensure that women are not left shouldering the bulk of the burden for building-back better, bound by portrayals of vulnerability and virtuousness. On this point, Enarson [75] observed in the aftermath of Hurricane Katrina that men were particularly active in the highly visible, immediate rescue and clean-up and operations, while the arduous labours and practices of care undertaken by women (and women of colour in particular) in the longer term remained both 'exceptional and exceptionally invisible'. In her examination of the experiences of women and girls displaced by Typhoon Haiyan, Tanyag [20] showcases the immediate and long term costs of post-disaster recovery and rehabilitation on female bodily autonomy and integrity, revealing "how the postdisaster survival of families and communities depends on intensified demands for selfsacrificing acts ... from women and girls ...[who] do not necessarily share in the distribution of material resources in the wake of disaster because their productive and reproductive contributions remain undervalued, uncounted, and unpaid'. Similar findings following Hurricane Mitch in Nicaragua have prompted Bradshaw [38] to warn of an emerging 'feminisation of disaster response',

Given the extent to which resilience has permeated the lexicon of international agendas and is therein implicated in the global political economy, an understanding of how this neoliberal imperative [76,77] is infiltrating the social reproductive sphere and reconfiguring the 
Ramalho - Engendering disaster risk management and resilience-building: the significance of the everyday in evaluations of the exceptional

everyday is of great importance given the 'blurred lines between the global and the household' [34] (see also [32,35,36]). Furthermore, as Elias and Roberts [30] poignantly assert:

'The everyday is not just an interesting lens through which to make sense of the global political economy. It is also a site of ongoing gendered political struggles... [I]t is a site within which battles are fought over women's appropriate role in economic life, who cleans and cares for the children, how working lives are experienced and whose leisure time counts for most. It is also a site within which economic reforms touch down and reshape the lives of the most vulnerable and a site within which neoliberal reform projects are resisted and challenged.'

Having summarised the literature informing my epistemological stance on the significance of the everyday within evaluations of the exceptional, in the section that follows, I will explore the utility of this conceptual lens by applying it to the case of low-income disaster-prone neighbourhoods in Metro Cebu.

\section{Methodology}

The data presented below was collected during ethnographic fieldwork conducted between 2016 and 2017 across five informal settlements in Metro Cebu, which frequently experience various anthropogenic and environmental hazards, and collectively encompass a diverse range of topographic, geographic and environmental characteristics. Contact with respondents was facilitated by FORGE, a local non-governmental organisation that supports the urban poor to address issues of land tenure insecurity, access to basic services, and DRRM, namely by building the capacities of homeowner associations. Local association members were invited to participate in focus group discussions (ten conducted in total with 61 individuals, 60 percent of whom were female) and/or in-depth interviews (44 in total, 66 percent female participants), exploring gendered perceptions and experiences of risk, insecurity and disaster, and participation in local risk management activities. More than half of the interviews incorporated an auto-photographic activity to enable respondent-led dialogue and life storytelling using nonverbal, visual mediums. Though the vignettes presented below are drawn predominantly from one community, the themes that emerge reflect the broader issues highlighted by respondents across the study sites.

\section{Absent infrastructure and everyday risk: the materiality of the political}

\subsection{Everyday risk and the politics of infrastructure provision}

Mother of five, Janet (42yrs) lives in the hilly outskirts of Cebu City, on a state-owned resettlement site for low-income households evicted from danger zones. She and her family 
Ramalho - Engendering disaster risk management and resilience-building: the significance of the everyday in evaluations of the exceptional

moved here in 2006, following their forced eviction from publicly-owned land in the port area downtown which had been earmarked for commercial development. Relaying her memories from this period, she said:

'We really didn't have [a] choice but to move here and stay here. It was very difficult for us because we had to walk very long distances. Before when we first stayed here, we had lots of problems. There was no water, no electricity, a lot of trash... We were very scared to be here... [W] e would have to walk through the river because there were no roads. So if there was a flood or overflowing of the river, we would have to get a rope to guide us in the river. Even motorcycles would go through the river, but not in the rainy season. It was really normal for them to have accidents. I myself have experienced that twice'.

In the several years that have passed since Janet's family (who were among the first residents) was relocated, incessant lobbying by local homeowner associations for infrastructural improvements eventually resulted in water and electricity connections in $2012 / 2013$, although the quality and quantity of water remains problematic. A neighbouring resident, Sally (35yrs), told me that children in the community, including her own, were often sick with stomach problems and diarrhoea, a problem that she attributed to poor water quality. It tuned out her suspicions were correct. After ongoing complaints from residents, tests conducted by the city revealed high levels of faecal matter in the water; water it should be noted, that residents were purchasing from a private supplier in the absence of a connection from the city's main provider, the Metropolitan Cebu Water District. Sally had previously worked as a childminder near where she had been living downtown, but told me that shortly after moving here, she 'decided to resign from my work because my second youngest kept getting sick so I decided to stop working and focus on taking care of her. So that is why now it is more difficult, because I do not have a regular income.' Following a recent bout of sickness, Sally was forced to take out a loan from a private lender to help cover the costs of the hospital bills, exacerbating their circumstances of financial insecurity. Her story reinforces the importance of understanding and analysing urban risks as a continuum rather than as distinct and unrelated issues [24], and the multiple socio-material embodiments of land tenure and infrastructural exclusions.

Edelita (65yrs), a widow who lives with her daughter (also widowed) and six grandchildren, told me it was the journeys of her grandchildren to and from school that she worried about most on a daily basis, 'afraid of rape, or that they will fall and get injured on the slopes.' At the time of my initial visit to the community in February 2016, the main roads connecting residents to the city remained unpaved and in very poor condition, despite the original request for concreting dating back as far as 2010. Across both the focus group discussions and individual interviews, men and women spoke to me at length about the 
Ramalho - Engendering disaster risk management and resilience-building: the significance of the everyday in evaluations of the exceptional

challenges they faced because of the steep topography and ongoing deficiencies in basic infrastructure provision, with the absence of paved roads repeatedly identified as one of the main risks affecting residents, especially the men. No longer having the diversity of livelihood options that had been available to them in the downtown port area, many now worked as habalhabal (motorcycle taxi) drivers which was the only means of motorised transport into or out of the neighbourhood, and seen to be one of the few local income-generating options for men with limited education and vocational training. In addition to hampering their ability to work, the condition of the roads also exacerbated residents' overall sense of vulnerability. According to Nelson (35yrs), who moved to the area in 2011:

'The roads are very bad here. My motorcycle cannot make it through the mud. Access to the hospital is also a major issue. There is no transportation to get there because there are no roads so you cannot travel there. If you are sick and have to go to the hospital, there is a fifty-fifty chance that you will die.'

Health and environmental risks stemming from improper solid waste management were also exacerbated by the state of the roads, as government utility vehicles are only able to reach the base of the community, requiring families, most notably female members, to carry household waste down the hill to the trucks. Describing her frustration with waste collection, mother of seven Bebe (33yrs) explained: 'the trucks can't really come up here so they ring the bell for us so that we know that they are there, so we need to go down and carry our garbage to them. But by the time that we reach the bottom they have already gone off, they don't wait for us to reach them'. After trekking into the valley only to find that the trucks have gone, she said that most residents leave their bags of refuse near the road entrance until the next collection. In the interim, materials often wind up in the nearby river, blocking the flow of water and in turn contributing to floods, outbreaks of dengue and waterborne diseases, as described by Sally.

According to residents, the slow pace of infrastructural development in their neighbourhood was a consequence of local electoral politics and their lack of political accountability. Officially, the relocation site falls under the jurisdiction of barangay Busay, however in the absence of a clearly defined border, some of the residents have registered with neighbouring barangay Lahug. This ambiguity over which barangay is responsible for the settlement, and the associated fact that barangay captains in both areas cannot guarantee the electoral support of the residents, gives politicians little incentive to invest in and develop the space. Frustrated by the absence of basic infrastructure and government inaction, Manuel (43yrs), who is married with five children and works as a security guard and habal-habal driver on the side remarked: 
Ramalho - Engendering disaster risk management and resilience-building: the significance of the everyday in evaluations of the exceptional

'Lahug and Busay local government units are always quarrelling on who will be accountable for this sitio. There is no guidance from the government on how to solve this problem because there is no political will. My solution is that [this] sitio should be a new barangay, because right now we cannot avail of any help for projects from the government.'

As further evidence of this political apathy, when I asked Busay's Chairman about waste collection in the area, he told me:

'The barangay takes a small truck... and we collect there [but] the people there will not go down. [They] are lazy and throw their garbage. They are very lazy. Once they saw the garbage truck already they will not go down, they will just wait until they are going down, going to school and they will just leave it there in the roads... So that is a problem for us.'

Gauging from these and earlier remarks where he described the community's notoriety for guns, drugs, and residents 'quarrel[ling] ... and shoot[ing] each other', pejorative stereotypes of the urban poor as 'lazy', criminal and subsequently undeserving may also be fuelling the barangay's neglect of local residents.

Landslides were another shared source of concern among residents, as voiced by mother of four Daya (38yrs): 'whenever there are floods or heavy rains, we are in danger.' Samuel (53yrs) lost part of his house to a landslide a few years back: 'Every time there is a heavy rain, we might be covered in mud. It is very scary.' Showing me around the single room shack that housed him, his wife and four of his children, he said:

'most of the materials it is constructed from came from my previous house... [T] he compensation that they [the government] gave us [for relocating] really wasn't enough... The wood is starting to rot so it is really not a stable house... Before it was bigger, but a landslide destroyed it'.

He and his wife now slept outside under a makeshift awning so that their children could sleep inside. Many questions remain as to what the government was thinking in purchasing a relocation site where the natural topography lends itself to landslides and makes day-to-day mobility both difficult and expensive for residents. The unfathomability of this act is all the more so when households are being evicted and displaced because they are living in 'danger zones', and then moved into an equally if not more precarious set of circumstances.

\subsection{Filling the gaps: invisible labours of resilience}

The absence of basic services, lack of accountability and protracted bureaucracy described by residents was not unique to this neighbourhood, but a common challenge recounted by respondents across Metro Cebu. As indicated above, these infrastructural exclusions have 
Ramalho - Engendering disaster risk management and resilience-building: the significance of the everyday in evaluations of the exceptional

distinct gendered implications, and akin to Truelove's [13] and Tanyag's [20] findings, are particularly burdensome on women whose social reproductive responsibilities for ensuring the health and wellbeing of their family are exacerbated. Residents adopted various practices to manage the risks associated with inadequate drainage and sporadic waste collection services, as articulated by Nilda (50yrs) who lives on a privately owned, low-lying settlement near the city centre:

'After the rain there is always lots of trash that floats into the pathway so I always want to clean it... It is a usual occurrence here that when it rains, the water levels in this pathway rises, so we have been continuously adding more land into it, but it keeps on coming back again and again, and with it comes the trash from the areas surrounding our community... The water is very dirty so our place is also dangerous with mosquito infestations that are roaming around our community and cause sickness'.

Recounting her daily routine, Nilda's neighbour Bernadita (45yrs) said: 'If I do not drain the water [manually], then the water will come inside [my house]. Every morning, after I do the laundry or after we take a bath, we have to do this because the canal is stuck up in that area... because of garbage.' The burning of household waste was also common practice, the fires often timed to coincide with the hours most prone to dengue mosquitoes, the smoke helping to keep them away. Local homeowner associations also organised monthly environmental clean-up and infrastructure maintenance activities; collective initiatives that I have previously argued 'are rarely shared in practice' [19], with female volunteers largely outnumbering male participants, reinforcing normative (and unequal) gendered stereotypes and divisions of labour. As Tanyag [20] contends, narratives that celebrate community resilience assume, expect and depend on the elasticity of women's altruism and unpaid care work, exacerbating the depletion of women's bodies while also obscuring not only the feminisation of survival, but also 'the importance of the state in addressing structural gendered inequalities that impact women's and girls' experiences during and after disasters' [20].

Fires were another common threat affecting informal settlements across Metro Cebu; a scary reality reaffirmed by testimonies of respondents in all areas, many of whom had lost their homes, some, more than once, to fire. They were also ubiquitously the most feared of events traditionally conceived of within the realm of disasters, owing to their dangerous and destructive nature. Mother of four Lorna (35yrs) had twice lost her home to fire, a threat that was heightened in recent months following the construction of a fence around her settlement by the private developers of the adjacent lot. When I asked her how she was managing under these circumstances, she replied: 'One of my preparations for example, is when I want to go out, I don't go to places that are far from my home, in order that if there is an emergency, I can go 
Ramalho - Engendering disaster risk management and resilience-building: the significance of the everyday in evaluations of the exceptional

back and save my things and take care of my children.' Lorna's tactic of staying close to home was not unique to her, bringing to light the ways in which fire risk and land tenure insecurity interact to curtail female mobility, with massive implications for women's wellbeing and access to economic and social opportunities.

Another female interview respondent who had recently lost her home to a fire for the second time, and at the time of our conversation, was temporarily living (alongside several hundred other households) in the derelict parking lot of an abandoned convention centre on the instruction of the municipal government, recounted the impacts of the fire on her family: 'we are [always] spending... we have to pay one item is 20 pesos, another item is 20 pesos. We have two [generators] because you know an electric fan is so important because on the night it is so hot, so with a light and an electric fan it is 40 pesos. It is too expensive.' Though she and her husband had both managed to keep their jobs after the fire, hers as a housekeeper, and his as a barber, finances were tight, and often a source of marital conflict that in the past had become violent:

'A barber makes so much money. But he only gives us 200 pesos a day.... when you count [this money]... minus the fare and the rice, you know you cannot buy [what you need]. But I just receive it, it is tiring to always be asking about it. You know we have lots of fighting, you know he wants to hit me. This is the worst thing that he did [points to a scar on her face].'

To manage under the circumstances, she like many of her female neighbours had taken out loans from private lenders and purchased things where possible on credit. Her story of resilience reinforces Bradshaw and Fordham's [3] notion of the double disasters and the secondary impacts of housing and financial insecurity and gender-based violence that emerge in the aftermath of the events. Read alongside earlier accounts of the invisible costs of survival and resilience when living under a constant threat of flooding, dengue, fire and eviction, these narratives also collectively reveal the relationship between everyday and exceptional risk, as well as the continuum between social reproduction in times of crisis and the material and ideological conditions that restrict women's bodily autonomy in everyday life' [36].

\subsection{Continuums of risk and the materiality of the political}

As the above testimonies showcases, perceptions of, and encounters with risks among people living in danger zones are predicated on recurrent cycles of poverty and land tenure insecurity that interact with other forms of social, material and political disadvantage. Adapting Farmer's 
Ramalho - Engendering disaster risk management and resilience-building: the significance of the everyday in evaluations of the exceptional

[78] notion of the 'materiality of the social'1, the experiences articulated by respondents highlight what I call the 'materiality of the political', denoting the micropolitics of structural violence afflicting urban poor informal settlers, and specifically the material and spatial embodiments of risks that are produced and reinforced through sustained infrastructural and political neglect. Furthermore, these infrastructural exclusions relating to roads and transportation, water, sanitation, and garbage materialise in distinct classed and gendered riskscapes that are intimately connected with gendered roles and identify, and specifically with an intensification of everyday social reproductive labours that are fundamental to maintaining and building to individual and collective resilience (see also [18,19]). My findings on the significance of everyday risk over more exceptional catastrophic events mirror those of Cannon and Müller-Mahn [79], who noted a general absence of 'disasters' in discussions about risk at a community level, and the higher priority awarded 'to problems like illness, water supply, security, unemployment or traffic accidents.' Although floods, fires, and landslides featured prominently in my discussions with respondents, all hazards which qualify within normative conceptualisations of disasters, in the majority of cases, these events passed unnoticed by those outside the settlements and garnered little if any attention, support, or resources from the state despite their significance and adverse implications for local residents.

Interestingly, the term disaster was rarely used by respondents, apart from during the focus group discussions, when after a lengthy conversation about local risks, I asked participants what the term disaster ${ }^{2}$ meant to them and whether they had ever experienced one. In the ensuing conversations, perceptions of disaster were intimately tied to personal experiences of fear, trauma and loss, as summarised by a male respondent: 'I connect disaster with fatalities, loss of lives, loss of livelihoods, loss of properties and loss of opportunities. So disaster is about loss'. Many focus group respondents referred back to stories they had shared in earlier discussions about their experiences of fires and/or landslides that destroyed their homes. Talk of 'disaster' also elicited memories of other events, such as a flash flood that killed a local woman who had been doing laundry by the river, as well as typhoons Ondoy and Yolanda, and the recent (2013) earthquake in neighbouring Bohol, whose tremors were felt in Cebu. The inclusion of these latter three events in respondents' narratives of disaster seemed to have been

\footnotetext{
${ }^{1}$ For Farmer [78] this term serves as a prompt for ethnographic researchers interested in structural violence, to keep 'the material in focus', based on his 'conviction that social life in general and structural violence in particular will not be understood without a deeply materialist approach to whatever surfaces in the participant-observer's field of vision - the ethnographically visible... The adverse outcomes associated with structural violence- death, injury, illness, subjugation, stigmatisation, and even psychological terror-come to have their "final common pathway" in the material.' ${ }^{2}$ Here I used the English term 'disaster' alongside the Cebuano terms 'kalamidad' and 'katalagman' denoting calamity, catastrophe, danger and disaster, to prompt discussion.
} 
Ramalho - Engendering disaster risk management and resilience-building: the significance of the everyday in evaluations of the exceptional

influenced in part by national and international framings of these incidents as such. I say this because bar a few exceptions, (thankfully) most of their accounts were as temporary evacuees and/or peripheral witnesses to the catastrophe that ensued in other parts of the country, rather than as direct victims of these events themselves.

Also particularly illuminating in the focus group discussions was the attribution of 'disasters' to either deistic or natural forces, through statements such as: 'it is a punishment from God' or '[i]t is only God who knows what will happen. It [disaster] comes from God and it is in the Bible'. In another such discussion, typhoons were said to 'come from the sea', while flooding was said to be human-induced as well because people cut down trees and throw garbage everywhere. But with earthquakes, it is God'. Respondents equally appeared to share the perspective that 'disasters' necessitated individual vigilance, planning and preparedness, as articulated by a female respondent: 'Before a disaster happens you should be prepared... I make preparations for typhoons for example by preparing food, gathering canned goods, and such things but this is not enough to protect us.' Her comments reflected a subtle difference in the consensus articulated in preceding discussions about 'risks', where much of the accountability for managing and responding to these issues was ascribed to the local government, or attributed to community members' behaviours, intimating a more collective responsibility.

It appears that the term 'disaster' denotes a degree of unpredictable devastation; hence the attribution of such events to 'Acts of God'. Relatedly, as highlighted by Hulme [80], the connection between people and the natural environment is often purposefully understated to facilitate particular agendas of development and environmental pilfering, the use of the term 'natural' adjacent to 'disaster' thereby erasing the historical and social dimensions of vulnerability and the production of risk. My analysis of respondent narratives leads me to conclude that endorsing and propagating a language of 'disaster' over 'risk', which inadvertently frames these happenings as unforeseeable, unpreventable and exceptional, serves to depoliticise debates on risk and vulnerability. It also simultaneously (and problematically) places the onus on individuals, more than governments it would seem, to prepare for the unexpected, and to assume responsibility for response, recovery and resilience in the aftermath of such events, in addition to surviving under the circumstances of precarity that characterise their everyday. As I have argued, these responsibilities are not shared uniformly across society, or within households, but instead are deeply classed and gendered, bound by existing structures of inequality and divisions of social reproductive practices of care (see also $[18,19]$ ).

\section{Conclusion}


Ramalho - Engendering disaster risk management and resilience-building: the significance of the everyday in evaluations of the exceptional

In this article, I have suggested a framework for engendering DRRM and resilience scholarship and practice rooted in feminist conceptualisations of 'the everyday'; a term that encompasses 'the mundane' practices and relationships of everyday life and survival, and the subjective meanings and embodiments of these processes and encounters from people's personal perspectives [30]. Though the concept of the everyday and its associated ideological standpoint that the personal is political have long foregrounded feminist research across disciplines, their application within the field of DRRM, climate change and resilience remains relatively new, perhaps owing to the overarching concern of these sectors with exceptional and unparalleled phenomenon. Recognising the limitations of objectivist, hazard-oriented, techno-scientific solutions, this article contributes to efforts to advance more nuanced and intersectional approaches to DRRM and climate change adaptation that prioritise the rights and wellbeing of citizens first and foremost within urban resilience-building agendas [20,22].

My intention here is not to discount the importance of researching and understanding extreme catastrophic events. Rather, I have argued that the everyday must maintain a space of significance within analyses of the exceptional. Attentiveness to the everyday can help to uncover the multiple and often invisible ways in which environmental change, infrastructural exclusions, and moments of crisis are experienced, and intimately enmeshed in socio-political power structures and protracted experiences of precarity. Indeed, my use of this conceptual frame to analyse the ethnographic vignettes from women and men living in disaster prone neighbourhoods in Metro Cebu reveals that risk, insecurity and disasters operate as a continuum and constitute an everyday reality for many, with multiple and often invisible impacts that are aligned with pre-existing forms of gender and class subordination that span the so-called productive and reproductive domains.

Moving beyond labels of gendered vulnerability, the lens of the everyday draws attention to what I have termed the 'materiality of the political', exposing the multiple material and affective gendered embodiments of risk and resilience that are produced and reinforced through sustained infrastructural exclusion, political neglect and entrenched gender inequalities. These findings highlight the centrality of safe and affordable housing, sustainable livelihoods and access to basic infrastructure to urban DRRM, and women's critical, yet all too often undervalued and unrecognised contributions to resilience-building. They also render visible the recurrent crises, double disasters, and persistent conditions of insecurity afflicting many urban poor informal settlers, directing attention to the complex dynamics and actors implicated in the gendered political economy of disaster risk in Metro Cebu. Relatedly, my analysis of focus group discussion narratives about risk and disaster reveals a subtle yet 
Ramalho - Engendering disaster risk management and resilience-building: the significance of the everyday in evaluations of the exceptional

significant discursive dynamic, wherein the term 'disaster' inadvertently conjures ideas of risk as exceptional, unforeseeable and thus unpreventable. This language, I have argued, serves to obscure the ways in which the Philippine state, the private sector other actors are directly implicated in the production of risk, vulnerability and disasters, and deflects accountability and attention away from the 'everyday' risks that have a greater impact on people's day-to-day wellbeing, while also placing the onus on affected communities to be resilient. When these dynamics are considered alongside global trends that point to a feminisation of DRRM and resilience [18-20,38,75], it becomes clear that so long as we continue to adopt a siloed, hazardoriented focus on large-scale catastrophic events, rather than considering them in relation to everyday realities, practices, and inequalities, efforts to engender DRRM and resilience-building are unlikely to be realised.

\section{Acknowledgements}

This article would not have been possible without the support of FORGE, the women and men in Cebu who generously shared their time and stories with me, and Regina Yoma who has worked with me over the years as my interpreter. I would also like to thank Sylvia Chant for her mentorship, guidance and constructive comments throughout the research process, and the anonymous reviewers for their helpful feedback. The research on which this article is based was generously supported by an Economic and Social Research Council Postgraduate Award (ES/J500070/1, award reference 1510364).

\section{References}

[1] S. Bradshaw, Gendered Rights in the Post-2015 Development and Disasters Agendas, IDS Bull. 46 (2015) 59-65.

[2] UNISDR, Making Disaster Risk Reduction Gender-Sensitive: Policy and Practical Guidelines, Geneva, 2009.

[3] S. Bradshaw, M. Fordham, Double Disaster: Disaster through a Gender Lens, in: Hazards, Risks and, Disasters Soc., Elsevier Inc., 2015: pp. 233-251.

https://doi.org/10.1016/B978-0-12-396451-9.00014-7.

[4] S. Chant, The 'feminisation of poverty'and the 'feminisation'of anti-poverty programmes: Room for revision?, J. Dev. Stud. 44 (2008) 165-197.

[5] S. Chant, Women, girls and world poverty: empowerment, equality or essentialism ?, Int. 
Ramalho - Engendering disaster risk management and resilience-building: the significance of the everyday in evaluations of the exceptional

Dev. Plan. Rev. 38 (2016) 1-24.

[6] A. Cornwall, Revisiting the "gender agenda," IDS Bull. 38 (2007) 69-78. https://doi.org/10.1111/j.1759-5436.2007.tb00353.x.

[7] C. Jackson, R. Pearson, Interrogating development, feminism, gender and policy. Feminist Visions of Development. Gender Analysis and Policy, in: C. Jackson, R. Pearson (Eds.), Fem. Visions Dev., Routledge, London, 1998.

[8] C. McIlwaine, K. Datta, From feminising to engendering development, Gender, Place Cult. 10 (2003) 369-382.

[9] S. Federici, Caliban and the Witch: Women, the Body and Primitive Accumulation, Autonomedia, (Brooklyn, NY, 2004.

[10] A. Escobar, Encountering development: The making and unmaking of the Third World, Princeton University Press, Princeton, NJ, 1995.

[11] A. Oliver-Smith, Theorizing Vulnerability in a Globalized World: A Political Ecological Perspective, in: G. Bankoff, G. Frerks, D. Hilhorst (Eds.), Mapp. Vulnerability Disasters, Dev. People, Earthscan, London, UK, 2004: pp. 10-24.

[12] G. Bankoff, Rendering the world unsafe:'vulnerability'as western discourse, Disasters. 25 (2001) 19-35.

[13] Y. Truelove, (Re-)Conceptualizing water inequality in Delhi, India through a feminist political ecology framework, Geoforum. 42 (2011) 143-52.

[14] F. Sultana, Suffering for water, suffering from water: Emotional geographies of resource access, control and conflict, Geoforum. 42 (2011) 163-72.

[15] F. Sultana, Fluid lives: Subjectivities, gender and water in rural Bangladesh, Gender, Place Cult. 16 (2009) 427-444.

[16] E. Enarson, What women do: gendered labor in the Red River Valley flood, Environ. Hazards. 3 (2001) 1-18.

[17] E. Enarson, B.H. Morrow, eds., The Gendered Terrain of Disaster: Through Women's Eyes, Praeger, New York, 1998.

[18] J. Ramalho, Hope, home and insecurity: gendered labours of resilience among the urban poor of Metro Cebu, the Philippines, Environ. Plan. D Soc. Sp. (2020), https://doi.org/10.1177/0263775820959337. 
Ramalho - Engendering disaster risk management and resilience-building: the significance of the everyday in evaluations of the exceptional

[19] J. Ramalho, Empowerment in the era of resilience building: gendered participation in community-based (disaster) risk management in the Philippines, IDPR. 41 (2019) 129148.

[20] M. Tanyag, Resilience, Female Altruism, and Bodily Autonomy: Disaster-Induced Displacement in Post-Haiyan Philippines, Signs J. Women Cult. Soc. 43 (2018) 563-585.

[21] S. Bradshaw, Engendering development and disasters, Disasters. 39 (2015) S54-S75. https://doi.org/10.1111/disa.12111.

[22] G. Ziervogel, M. Pelling, A. Cartwright, E. Chu, T. Deshpande, L. Harris, K. Hyams, J. Kaunda, B. Klaus, K. Michael, L. Pasquini, R. Pharoah, L. Rodina, D. Scott, P. Zweig, Inserting rights and justice into urban resilience: a focus on everyday risk, Environ. Urban. 29 (2017) 123-138.

[23] D. Satterthwaite, S. Huq, M. Pelling, H. Reid, P.R. Lankao, Adapting to Climate Change in Urban Areas: the possibilities and constraints in low-and middle-income nations, 2007.

[24] H.A. Ruszczyk, A continuum of perceived urban risk - from the Gorkha earthquake to economic insecurity, Environ. Urban. 30 (2018) 317-32.

[25] L. Bull-Kamanga, K. Diagne, A. Lavell, E. Leon, F. Lerise, H. MacGregor, A. Maskrey, M. Meshack, M. Pelling, H. Reid, D. Satterthwaite, J. Songsore, K. Westgate, A. Yitambe, From everyday hazards to disasters: the accumulation of risk in urban areas, Environ. Urban. 15 (2003) 193-204.

[26] B. Wisner, P. Blaikie, T. Cannon, I. Davis, At risk: natural hazards, people's vulnerability and disasters, Routledge, 2004.

[27] E. Enarson, A. Fothergill, L. Peek, Gender and Disaster: Foundations and Directions, in: Handb. Disaster Res., Springer, New York, 2007: pp. 130-146.

[28] S. Bradshaw, M. Fordham, Women, girls and disasters. A review for DFID, 2013. https://www.gov.uk/government/uploads/system/uploads/attachment_data/file/2366 56/women-girls-disasters.pdf.

[29] M. Fordham, The Intersection of Gender and Social Class in Disaster: Balancing Resilience and Vulnerability, Int. J. Mass Emerg. Disasters. 17 (1999) 15-36.

[30] J. Elias, A. Roberts, Feminist Global Political Economies of the Everyday: From Bananas to Bingo, Globalizations. 13 (2016) 787-800. 
Ramalho - Engendering disaster risk management and resilience-building: the significance of the everyday in evaluations of the exceptional

[31] C. Katz, Vagabond Capitalism and the Necessity of Social Reproduction, Antipode. 33 (2001) 709-728.

[32] I. Bakker, Social reproduction and the constitution of a gendered political economy, New Polit. Econ. 12 (2007) 541-556.

[33] C. Enloe, Seriously! Investigating crashes and crises as if women mattered, University of California Press, Berkeley, 2013.

[34] J. Elias, S. Rai, The Everyday Gendered Political Economy of Violence, Polit. Gend. 11 (2015) 424-429.

[35] M. Tanyag, Invisible labor, invisible bodies: how the global political economy affects reproductive freedom in the Philippines, Int. Fem. J. Polit. 19 (2017) 39-54. https://doi.org/10.1080/14616742.2017.1289034.

[36] M. Tanyag, Depleting fragile bodies: The political economy of sexual and reproductive health in crisis situations, Rev. Int. Stud. 44 (2018) 654-671. https://doi.org/10.1017/S0260210518000128.

[37] UNISDR, Terminology on Disaster Risk Reduction, 2009. http://www.unisdr.org/we/inform/terminology.

[38] S. Bradshaw, Gender, development and disasters, Edward Elgar Publishing, Cheltenham, 2013.

[39] S. MacGregor, A stranger silence still: The need for feminist social research on climate change, Sociol. Rev. 57 (2009) 124-140.

[40] G. Terry, No climate justice without gender justice: An overview of the issues, Gend. Dev. 17 (2009) 5-18.

[41] F. Denton, Climate change vulnerability, impacts, and adaptation: Why does gender matter?, Gend. Dev. 10 (2002) 10-20.

[42] A. Allen, T. Belkow, S. de los Ríos, C.E. Estrada, R. Lambert, L. Miranda, R. Poblet, L.Z. Soto, Urban Risk: In Search of New Perspectives, London, 2015. www.climasinriesgo.net.

[43] W.N. Adger, Vulnerability, Glob. Environ. Chang. 16 (2006) 268-281.

[44] A. Lavell, E. Mansilla, D. Smith, A. Brenes, L. Romano, H. Somarriba, L. Gamarra, F. Armien, Local risk management: notions and precisions on concepts and practice, 2003. 
Ramalho - Engendering disaster risk management and resilience-building: the significance of the everyday in evaluations of the exceptional

[45] H.-M. Füssel, Vulnerability: A generally applicable conceptual framework for climate change research, Glob. Environ. Chang. 17 (2007) 155-167.

[46] T. Cannon, Vulnerability analysis and the explanation of 'natural'disasters, in: A. Varley (Ed.), Disasters, Dev. Environ., John Wiley \& Sons, 1994: pp. 13-30.

[47] M.K. Alvarez, K. Cardenas, Evicting Slums, 'Building Back Better': Resiliency Revanchism and Disaster Risk Management in Manila, Int. J. Urban Reg. Res. 43 (2019) 227-249.

[48] M.K.O. Alvarez, Discourses of 'Danger Zone' Slum Evictions and the Aestheticization and Territorialization of Disaster Risk in Post-Ondoy Manila, University of the Philippines Diliman, Quezon City, 2018.

[49] J. Ramalho, Worlding Aspirations and Resilient Futures: Framings of Risk and Contemporary City-Making in Metro Cebu, the Philippines, Asia Pac. Viewp. 60 (2019) $24-36$.

[50] D. Dodman, J. Hardoy, D. Satterthwaite, Urban development and intensive and extensive risk: Background paper for the ISDR Global Assessment Report on Disaster Risk Reduction, 2009.

[51] S. Bartlett, D. Dodman, J. Hardoy, D. Satterthwaite, C. Tacoli, I.I. for E. and D. IIED, I.I. de M.A. y D. IIED-America Latina, Social Aspects Of Climate Change In Urban Areas In LowAnd Middle Income Nations, 2009.

[52] C. Moser, D. Satterthwaite, Toward pro-poor adaptation to climate change in the urban centers of low-and middle-income countries, in: R. Mearns, A. Norton (Eds.), Soc. Dimens. Clim. Chang. Equity Vulnerability a Warm. World, 2010: pp. 231-258.

[53] S. Kovats, S. Lloyd, N. Scovronick, Climate and health in informal urban settlements, 2014. http://pubs.iied.org/pdfs/10719IIED.pdf.

[54] K. Hewitt, Regions of risk: A geographical introduction to disasters, Routledge, New York, 1997.

[55] D. Dodman, D. Brown, K. Francis, J. Hardoy, C. Johnson, D. Satterthwaite, Understanding the nature and scale of urban risk in low- and middle- income countries and its implications for humanitarian preparedness, planning and response, London, 2013.

[56] N.E. and D.A. NEDA, NEDA LAUDS PH NEW POVERTY INDICATOR, (2018). http://www.neda.gov.ph/2018/11/22/neda-lauds-ph-new-poverty-indicator/. 
Ramalho - Engendering disaster risk management and resilience-building: the significance of the everyday in evaluations of the exceptional

[57] ILO, Statistical update on employment in the informal economy, 2012. http://laborsta.ilo.org/informal_economy_E.html.

[58] S. Chant, Women's roles in recession and economic restructuring in Mexico and the Philippines, Geoforum. 27 (1996) 297-327.

[59] S. Chant, C. McIlwaine, Women of a lesser cost: female labour foreign exchange and Philippine development., (1995).

[60] L. Lindio-McGovern, Neo-liberal globalization in the Philippines: Its impact on Filipino women and their forms of resistance, J. Dev. Soc. 23 (2007) 15-35.

[61] Y. Su, M. Tanyag, Globalising myths of survival: post-disaster households after Typhoon Haiyan, Gender, Place Cult. (2019) 1-23. https://doi.org/10.1080/0966369X.2019.1635997.

[62] E. David, E. Enarson, eds., The Women of Katrina: How Gender, Race, and Class Matter in an American Disaster, Vanderbilt University Press, Nashville TN, 2012.

[63] E. Enarson, Women Confronting Natural Disaster: From Vulnerability to Resilience, Lynne Rienner Publishers, Boulder, CO, 2012.

[64] E. Unterhalter, Gender and poverty reduction: The challenge of intersection, Agenda Empower. Women Gend. Equity. 23 (2009) 14-24.

[65] S. Bradshaw, S. Chant, B. Linneker, Gender and poverty: what we know, don't know, and need to know for Agenda 2030, Gender, Place Cult. 24 (2017) 1667-88.

[66] S. Chant, C. McIlwaine, Cities, Slums and Gender in the Global South: Towards a Feminised Urban Future, Routledge, London, 2016.

[67] S. Chant, M. Klett-Davies, J. Ramalho, Challenges and potential solutions for adolescent girls in urban settings: a rapid evidence review, London, 2017.

[68] J.C. Gaillard, K. Sanz, B.C. Balgos, S.N.M. Dalisay, A. Gorman-Murray, F. Smith, V. Toelupe, Beyond men and women: a critical perspective on gender and disaster, Disasters. 41 (2017) 429-447. https://doi.org/10.1111/disa.12209.

[69] R. Elmhirst, Introducing new feminist political ecologies, Geoforum. 42 (2011) 129-32.

[70] S. Doshi, The Politics of Persuasion: Gendered Slum Citizenship in Neoliberal Mumbai, in: R. Desai, R. Sanyal (Eds.), Urban. CitizenshipContested Spaces Indian Cities, Sage India, New Delhi, 2011: pp. 82-108. 
Ramalho - Engendering disaster risk management and resilience-building: the significance of the everyday in evaluations of the exceptional

[71] S. Doshi, The politics of the evicted: Redevelopment, subjectivity, and difference in Mumbai's slum frontier, Antipode. 45 (2013) 844-65.

[72] S. Doshi, Resettlement ecologies: environmental subjectivity and graduated citizenship in Mumbai, in: A. Rademacher, K. Sivaramakrishnan (Eds.), Ecol. Urban. India Metrop. Civility Sustain., Hong Kong University Press, Hong Kong, 2013: pp. 225-48.

[73] S. Doshi, Embodied urban political ecology: five propositions, Area. 49 (2017) 125-128.

[74] G. Bankoff, T. Cannon, F. Krüger, E.L.F. Schipper, Introduction: Exploring the links between cultures and disasters, in: Cult. Disasters Underst. Cult. Fram. Disaster Risk Reduct., Routledge, New York, 2015: pp. 1-16.

[75] E. Enarson, Women and girls last? Averting the second post-Katrina disaster, (2006). http://understandingkatrina.ssrc.org/Enarson/ (accessed July 16, 2015).

[76] M. Welsh, Resilience and responsibility: Governing uncertainty in a complex world, Geogr. J. 180 (2014) 15-26.

[77] C. Zebrowski, The nature of resilience, Resilience. 1 (2013) 159-173.

[78] P. Farmer, An Anthropology of Structural Violence, Curr. Anthropol. 45 (2004) 305-25.

[79] T. Cannon, D. Müller-Mahn, Vulnerability, resilience and development discourses in context of climate change, Nat. Hazards. 55 (2010) 621-635.

[80] M. Hulme, Why we disagree about climate change: Understanding controversy, inaction and opportunity, Cambridge University Press, Cambridge, 2009. 